Paideusis

\title{
Diverse School Populations and the Corresponding Need for Multiple-Identity Coalitions: With a Touch of Class
}

\section{Richard A. Brosio}

Volume 12, Number 1, 1998

URI: https://id.erudit.org/iderudit/1073094ar

DOI: https://doi.org/10.7202/1073094ar

See table of contents

Publisher(s)

Canadian Philosophy of Education Society

ISSN

0838-4517 (print)

1916-0348 (digital)

Explore this journal

Cite this article

Brosio, R. (1998). Diverse School Populations and the Corresponding Need for Multiple-Identity Coalitions: With a Touch of Class. Paideusis, 12(1), 23-36.

https://doi.org/10.7202/1073094ar 


\title{
Diverse School Populations and the Corresponding Need for Multiple-Identity Coalitions: With a Touch of Class
}

\author{
Richard A. Brosio, Ball State University, USA
}

\section{Introduction}

Public schools are characterized by important historical struggles conducted by those who seek to make education more answerable to the requirements of (1) bona fide democratic practice, (2) movement toward more social justice and greater inclusivity, and (3) respect for diversity-although not solely "free" market consumer-choice differences. 1 These struggles are against the imperatives of capitalism; hierarchies based on race/ethnicity, gender, and sexual orientation; as well as various social injustices based on socially constructed and invidious differences. The reach and power of the market make William Watkins' following insight relevant:

\footnotetext{
Diversity has apparently become (for some) an end in itself. Yet, (one) cannot help but raise questions about what "diversity" might mean in capitalist America. What does it mean in a society rigidly stratified by economic division? Does ethnic diversity challenge the economic arrangements of society? What does the (narrow) culturalist dialogue have to say about (social) class? ${ }^{2}$
}

All too often, diversity and pluralism "lite" lead to conceptualization and practice based on the faulty assumption that prejudice and mistreatment of the subaltern "other" is based solely upon irrationality, personality, and/or other psychological disorders, rather than on outrageously great asymmetries of power, income, wealth, access, and so on, that are politically constructed, instead of attributable to the "nature of things." I will ground the analysis of difference and identity within materiality and class although not in a reductionist or mechanistic-base-determines-superstructure manner.

\section{I}

Although the experiences of elementary and secondary students are different in many ways from those of adults, there are many similarities as well as correspondences between school and society; therefore, my arguments will treat the experiences of students, workers, and citizens as part of a seamless continuity. Christine Sleeter and Carl Grant have argued that

... social theory that criticizes unequal relationships among groups, and that illuminates how oppressive structures are reproduced and can be changed, is needed. There is a need to build a theory that integrates racism and sexism with class relations, and that does not treat two of these as subsidiary to the third. We believe that such theory-building should be done collectively by a group representing diverse race and class backgrounds and both sexes. Individuals in the group will need to prepare by familiarising themselves with the historic and contemporary experiences of their own race/class/gender groups, and of one of two other groups. During this preparation, individuals 
should seek answers to the following questions: Under what conditions has one group oppressed another group? Exactly what were the group boundaries? What strategies or power bases did a group use to subordinate another group, how was that relationship maintained, and how did the subordinate group respond? ${ }^{3}$

While we must pluralize the bases of domination and possible resistance beyond class, we must not subscribe to the current tendency to assert that there is an infinite and uncategorizable pluralism of identities and sites. Furthermore, the analyses of specificities should not keep us from relating our findings to concomitant work featuring macro-structures-including the global capitalist political economy. In spite of the theoretical difficulties inherent to relating micro- to macro-realities, the intellectual work must go forward. However, it is helpful to keep in mind that, "while we may not be able to conceptualize entirely the multiple parallel determinations, or the interplay of class, race, and gender in education, we can at least try to support the struggle to overcome discrimination, oppression, and the deep structuring of subjectivities with classist, racist, and gender-biased overtones." 4 Educators should be encouraged to think seriously about the continued correlation between school achievement and class. At this time, there is significant discussion among black intellectuals and journalists concerning their growing awareness that class may trump race. ${ }^{5}$

Cameron McCarthy explains how rapidly changing demographics in school and society suggest the need for commensurate change in our schools. Furthermore, these changes must include improvements for those who have been oppressed:

As school populations become more ethnically diverse, and as minorities have become majorities in many school districts the moral and practical support for the hegemony of Eurocentrism in the curriculum has been imperilled. Minority youth and women have (also) begun to offer a more systematic challenge to the structure of school knowledge (itself). Minority students are mounting "new" demands for democratization and diversity in the curriculum and course offerings .... This ... rupture with the dominant paradigm has made possible even more radical demands for critical antiracist and anti-sexist materials and practices. Moreover, it has been argued that curriculum and pedagogy for minority and majority youth should have an organic link to other experiences and struggles in society, with respect to such issues as the loss of infrastructural support and jobs .... . Such a new critical approach to the multicultural curriculum would also "celebrate the contributions of working people, women, and minorities to our general cultural pool" and would be the point of departure "for providing (subaltern) students with their own culfural capital." By insisting that radically diverse cultural knowledge(s) rooted in the ... experiences of oppressed groups should be introduced into the school curriculum, we can avoid the "benign" pluralism and cultural relativism that is now embodied in certain innocuous forms of multicultural education ... "Such pluralism tolerates the existence of salsa, it even enjoys Mexican restaurants, but it bans Spanish as a medium of instruction." 6

McCarthy draws upon Robert W. Connell's work, in particular, the latter's idea of "common learnings" which favours the generalized use of critical knowledge for all students not just for the sons and daughters of the middle-class, rich, and the powerful. I have referred to such knowledge as 
"getting at the physics of things," or coming to understand the underpinnings upon which a society rests, and/or power knowledge. Obviously, such a diffusion of critical/power knowledge would include taking into account and valuing the knowledge and experiences (hopefully, reflected upon experiences) of all students in our schools. In the end, such knowledge could prove to be counterhegemonic as well as enabling subaltern students to realize their situation, its causes, and perhaps some solutions. Carla O'Connor has conducted a study that provides evidence that six, low-income African-American adolescents could keep in mind both the need/possibility for high academic achievement, and the recognition of how race, class, and gender operated to limit the opportunities for people like themselves. In fact, 'these students' familiarity with struggle, including collective struggle, was the only biographical factor which distinguished them from other respondents in the large project of which they were a part. Thus, in contrast to the findings of some, their knowledge of struggle did not curtail their academic success, but may have contributed to their sense of human agency." 8

Instead of lip-service to salsa and/or subaltern heroes and holidays, a critical education would privilege common learnings resting upon warrantedly assertable arguments for positive democracy, social justice, and respect for bona fide diversity rather than the United Colours of Benetton. Such a critical approach must reflect the need for a broad epistemological input because, in a secular democracy, it is impossible to prove that any one person or group has a pipeline to certainty. The inclusion of multi-vocal articulations of lived experiences as well as critical/learned reflections upon them would make possible a series of challenges to previously unchallenged school and societal assumptions and practices. Such school reform could link students to progressive projects conducted by their parents and/or other adults. There are examples of such linkage from around the world.

What is being favoured herein stands in stark contrast to

a multicultural education which aims primarily at tolerance and acceptance of other cultures as a societal goal. In the process, this 'safe' multicultural framework either marginalizes or obfuscates the important issues of economic wealth and power underlying our society. This version of multiculturalism becomes 'safe' to those wielding economic and political power because social reforms can be introduced without altering fundamental relations of wealth and property ownership. ${ }^{9}$

The educational reforms I favour must be driven by broad coalitions of adults who challenge the state (central government) to act on behalf of the democratic rather than capitalist imperative, both of which influence school and state. ${ }^{10} \mathrm{Svi}$ Shapiro has articulated well how the democratic imperative has acted upon the state and schools in the U.S.; mutatis mutandis, what follows is roughly analogous to what has occurred in many countries characterized by de jure democratic governments as well as various forms of capitalism. In Shipper's view, educators who insist upon dealing with the "whole child," where the opportunity to learn is dependent upon physical and emotional well-being, have linked schooling to a broader concept of social services. The obvious examples are adequate health care and nutrition, good home environments, and assistance to students' families. He states that "[t]he notion of educational rights has (been) expanded to embrace a wider set of social rights" 11 and argues that this 
view of educating the "whole child" and educational/social rights is easily extended to generous protection for parents-for example, job and income maintenance support.

Following Shapiro, the kind of education I championed encourages students at least to consider that all too often democracy is celebrated as if it were separate from political economy. In this era of capitalist triumphalism and a totalizing new world-order under capital's aegis, certain celebrants of "democracy" proffer an electoral brand that is unfortunately

compatible with rigidly stratified and oppressive class systems. Such is the democracy of Mexico, the Philippines, or Mississippi, where one can vote even if one cannot eat. l.inking diversity and multiculturalism to improved communication, association, and democracy sounds empowering (to some) but contributes to a narrow discourse where questions about property ownership, wealth, and the state never arise. In this context, educating for democracy becomes a trite, meaningless construct. ${ }^{12}$

Education for democratic empowerment, social justice, and respect for bona fide diversity must get beyond a culturalist focus that leads to suggestions for behavioural changes and "solutions" ones that do not challenge the realities of power, privilege, access, and wealth. It is clear that racial and gender discrimination/oppression occur upon particular terrains and at specific historical times; moreover, currently, they occur within the contexts of capitalist work relations as well as capital's colonization of everyday life and for a rapidly increasing number of the world's people.

It is helpful to remember that there is no ultimate

'generative nucleus' . . . from which the rest of the pattern of general relations springs. There is . . . a unity in the field, an orderliness, which needs to be understood .... This unity is not the unity of a system, as functionalist analysis would imply ..... [Instead] it is a unity-always imperfect and under construction+(_) of historical composition. I mean 'composition' as in music: a tangible, active, and often difficult process of bringing elements into connection with each other and thrashing out their relationships. The product of the process is not a logical unity but an empirical unification. It happens on particular terms and in particular circumstances. $^{13}$

Critical progressive educators can help their students (and colleagues) understand this empirical unification which allows and/or disallows certain advantages. The literature on these advantages is rich and well-known, but beyond the scope of this work. However, the following passage from Kris Gutierrez represents well our need to look inside the school. Guitars has argued that:

critical multiculturalism requires a social transformation of the social relationships in the contexts and purposes for learning. Hegemony needs to be understood not only as the product of the larger social systems, but also as the roduct of the way individual classrooms and their social relations are organized and constructed. As we struggle for social heteroglossia, we must insist on the commingling of various socio-cultural perspectives and curricula that have both a political and socio-cultural conscience. To do so requires access to and participation in multiple public spheres in which people with diverse values, beliefs, and practices jointly construct new sets of relationships, interactional forms, and understandings of race, culture, and 
diversity (hopefully, class also). Ultimately, critical multiculturalism must challenge and reconstruct the hegemonic theories of multiculturalism so that issues of representation, the unequal distribution of power, economic and material resources, and access to educational institutions and (elsewhere) are taken up. ${ }^{14}$

The current demographic and socio-economic conditions in the U.S. and elsewhere make clear that a reconstructionist/liberatory school-society project must be comprised of those students and adults who are most affected by injustice and oppression of various kinds. Furthermore, a multiculturalism that is not reconstructionist is mostly an exercise in crowd control, careerism for educators, travel opportunities, attending around-the-world-food affairs while remaining at home, and allowing the demands of global capitalists to co-opt many multicultural courses and programs. Watkins has asserted that

committed progressive multiculturalists hope for curriculum and educational reform that is genuinely 'reconstructionist'-that is, capable of helping to alter fundamental societal arrangements. Conversely, those who strive to have reform protect the existing arrangements hope to maintain multicultural (and other areas of) education within safe boundaries. ${ }^{15}$

Holly Sklar has presented us with a grim picture of American society at the end of this millennium, one that provides evidence for the need of broadbased progressive coalitions aimed at changing the schools and socio-economic political systems of this country. His snapshot invokes passages from Jonathan Kozol's Savage Inequalities: Children in America's Schools (1991) and reminds us that Martin L. King urged Americans to choose community over chaos:
A true revolution of values will soon look uneasily on the glaring contrast of poverty and wealth .... There is nothing to prevent us from paying adequate wages to schoolteachers ... . There is nothing but a lack of social vision to prevent us from paying an adequate wage to every American citizen whether (s/)he be a hospital worker, laundry worker, maid, or day labourer. There is nothing but short-sightedness to prevent us from guaranteeing an annual minimum -and liveable-income for every American family. ${ }^{16}$

Sklar informs the reader that conditions King warned about have become a good deal worse since he was murdered in 1968. Wealth is rushing upward instead of trickling down. Although there are significant differences in school and societal conditions among developed countries which are capitalist and de jure democracies, the shredding of safety nets, the decline of secure and well-paying jobs, attacks on public institutions in the name of privatization, and market outcomes are all characteristic of "advanced" English-speaking countries as well as other G-7 members. Some have argued that the former "War on Poverty" has become a war on the poor. Far from pursuing the promise of equal opportunity, those who are most powerful in the U.S. (as well as their agents and minions) seek to label children as illegitimate, expect them to fail, attempt to fail them, fail many of them, and actually treat the children and adults of poverty's culture as enemies. Perhaps, some other countries are undergoing somewhat similar experiences. 
The need for multiple identity coalitions-that is, a politics of identity beyond but including social class-is attributable in large part to the historical failure to achieve socio-economic justice for all citizens, as well as others who live in various polities, and workers-including those who are engaged in unpaid labour. I maintain that we should not abandon the idea of citizen-worker as an axis around which to organize broad democratic coalitions; however, we must take seriously the fact that, as we relate to the polity and while we labour in order to shape recalcitrant matter, we do so as not just classed persons, but raced and rendered ones, also.

My having stressed the importance of the citizen-worker as the centrally most important category for a broad collective politics of reconstruction is not a Trojan Horse for the continued privileging of heterosexual, white, male, paid workers. However, the difficulties inherent to identity politics and demands for recognition are numerous: chief among them is the impossibility of giving special attention to each and every identity that comprises the human condition; relatedly, even if it were possible, how would claims for justice be evaluated among the myriad voices? Manifestly, an ever-expanding identity politics poses serious problems for those who wish to construct broad-based, radical democratic coalitions. The inclusiveness provided by the concept citizenworker is the sine qua non for the achievement of a profoundly reconstructed society within which each and every wonderfully diverse person is treated with the dignity and concern that is deserved.

It is within this politically realizable society where advocates of identity politics can best promote and achieve their historic, reasonable demands for justice and recognition. Although at present there are certain frustrations and injustices inherent to the human condition that politics cannot remedy, we are far from achieving a society where every human being is treated as a valuable "thou"; in fact, all too many human beings are treated as if they were "manipulable it[s]," as Martin Buber has explained. To claim that the human condition is not likely to be one of complete fulfilment, happiness, and justice is not a clandestine argument for some Rightist contentions that biology is fate, and/or that democratic politics cannot get beyond the guillotine and/or gulag.

Istvan Meszaros is correct to argue that "there cannot be social transformation without an agency and the only agency conceivable under the present condition is labour in the sense Marx was talking about and which we must rediscover for ourselves under present conditions." 17 Marx is relevant as long as capitalism remains the most powerful secular force on earth. It is capitalism and its dynamic, crises-ridden characteristics that most importantly provides the terrains upon and contexts within which the politics of identity are conducted. As we know, Marx did not choose the working class as the key agency for historical transformation because they suffered the most, but because of his assessment of their position on the map of socio-economic and political realities. Si Kahn, who has been a community organizer in the southern U.S., takes identity realities seriously such as race, gender, as well as social class as organizing principles. Although he concedes that critics might call his strategy "separatist," he explains that it is correct as a starting principle for it allows him to begin where various people are situated. In Kahn's view, the various persons 
demanding justice from identity bases must enter coalitions and work across racial, gender, and class lines. He explains that working-class organization is crucial to building a healthy society, especially during this period of capitalist offensive; however, he insists that "we are not strong enough to exclude significant numbers of people who potentially can be part of a progressive movement.",18

As I have already suggested, it should be enough to organize around a sign stating "I am a human being"; unfortunately, this is not possible. Classist, racist, sexist, elitist, homophobic, and misogynist language and practices persist, resulting in destructive divisions among us as well as casting some of us out into the wilderness of what Toni Morrison calls "serviceable otherness." During this period dominated by yet another capitalist "gale of creative destruction," it is especially difficult to recognize our common human condition. The predominance of the "[black]" market and Darwinian jungle has long prevented effective collective action by subaltern people-at least, in the short run. The leaders who emerge from among citizen-workers can and must be representative of the whole wonderful diversity of the human family-a family whose interests are best served by overcoming a hegemonic system backed by absurd amounts of direct coercive power. The radical democratic, anticapitalist struggle must be aimed at the cessation of history being made behind our backs. is not

Daniel Singer claims that what is most dangerous to the regime of capital

... sporadic rebellions or 'postmodern' antics. What it fears is that social discontent, the protest of women, the revolt of ecologists should be joined together for long-term action by the vision of a radically different society. Its propagandists have tried to convince people that there is no alternative and there can be none. ${ }^{19}$

Chantal Mouffe has reminded us that the goal of radical democracy is to deepen and broaden its logic in order to better connect diverse persons and their struggles. She believes that "such a task requires the creation of new subjectpositions that would allow the common articulation of anti-racism, anti-sexism, and anti-capitalism according to the principle of democratic equivalence." 20 I wrestle with the idea of equivalence, not in terms of persons' rights to decide for themselves where the sources of their pain and exploitation are coming from, but with regard to the possibilities for effective transformative agency.

To concretize class today means to understand the embarkation of class, race, gender, and sexual orientation. This need not prove to be divisive, although it appears to be more difficult to organize heterogeneous groups than those which are more homogeneous. One need only think of the contemporary British film, "Brassed Off," concerning Yorkshire union workers; and/or, the Italian film from the early 1960s, called "The Organizer," which portrays labour solidarity in Turin, Italy circa 1900, to understand the organizational advantages of cultural sameness. Obviously, class is, in part, lived through race, ethnicity, and gender. As Robin Kelley has argued

There is no universal class identity, just as there is no universal racial or gender or sexual identity. The idea that race, gender, and sexuality are particular whereas class is universal not only presumes that class struggle is . . . (a) race and gender-neutral terrain but takes for granted that movements focused on race, gender, or sexuality necessarily undermine class unity and, 
by definition, cannot be emancipatory for the whole. Don't get me wrong. I'm not giving priority to 'identity politics' over the struggle to dismantle capitalism .... Rather, I have trouble with ... (a) characterization of race, gender, and sexuality as narrow identity politics while 'class' . . rises above these identities. ${ }^{21}$

A broadened concept of what being a worker means and includes allows race, gender, and so on, to be more easily recognized as central to class politics. For example, a majority of contemporary workers are women, especially when one includes unpaid labour! An emancipatory movement in the name of the whole-in school and society-must take the "new social movements" seriously in order to construct an effective citizen-worker/class politics. I am not arguing for formal schooling that features the imposition upon teachers and students of the discourses to which I critically subscribe. However, I believe that genuine education must include systematic attention to the issues raised here, as well as those raised by critical theorists, radical democrats, and multiculturalists who take class seriously, as well as those who are convinced that bona fide democracy is incompatible with actual existing regimes of capital.

\section{III}

I now offer some of Nancy Fraser's arguments on differences and similarities with regard to various forms of oppression and liberatory possibilities. Her analysis in "From Redistribution to Recognition: Dilemmas of Justice in a 'Post-Socialist' Age" is helpful for constructing multiple-identity coalitions as central to radical democratic agency. She endeavours to unite the bases of identity politics with the universalistic tradition of class-based socialism. According to the journal's editor, Fraser contrasts the logic of an cconomics of redistribution with that of civic and cultural recognition. She argues that while socialism aimed to abolish the proletarian condition the new movements based on ethnicity, race, gender or sexual orientation often wish to maintain and assert a distinctive identity. In Fraser's view, there are bound to be tensions between the politics of "difference" and the politics of equality. Yet, each needs the other. Half-measures in the recognition of cultural identities, and in the redistribution of resources, may only reinforce a system of injustice and, in the long term, may backfire on those they were intended to help. In a more radical programme, a deconstructive approach to identity in which all views are altered should be allied to a thoroughgoing process of redistribution. ${ }^{22}$ It may be that in the late twentieth century the struggle for recognition is becoming the paradigmatic form of political conflict; moreover, demands for recognition often displace a politics for socio-economic redistribution as the supposed remedy for injustice; however, Fraser reminds us that such a shift is occurring on terrains characterized by increasing material inequality. She understands well that such inequality ranges from income through access to education and health care, and all the way to caloric intake and exposure to toxicity.

Considering the growing inequality of people's lives around the world and the paradigmatic shift to a new political imaginary based on identity, difference, recognition, and cultural domination, should we attribute the shift to what was once called false consciousness? Or, does the shift represent a long needed redress of "culture-blindness" within the older socialist imaginary? She seeks 
to occupy middle ground vis-à-vis these stark choices. Fraser is convinced that we must accomplish an unprecedented intellectual and practical task,

that of developing a critical theory of recognition, one which identifies and defends only those versions of the cultural politics of difference that can be coherently combined with the social politics of equality. In formulating this project, I assume that justice today requires both redistribution and recognition .... (We must learn) how to conceptualize cultural recognition and social equality in forms that support rather than undermine one another. It also means theorizing the way in which economic disadvantage and cultural disrespect are entwined. Then, too, it requires clarifying the dilemmas that arise when we try to combat both these injustices simultaneously. ${ }^{23}$

Fraser understands that political economy and culture are implicated and that justice requires both redistribution and recognition; nevertheless, for explanatory reasons she conceptually separates the two. Because socio-economic injustice is rooted in the political economy, which includes such things as the expropriation of the fruits of one's labour and deprivation for many due to an inadequate standard of living, the remedies require restructuring along the lines of altering radically the division(s) of labour, revising and publicly controlling investment policies, redistribution of income, and access to key resources. Cultural injustice is grounded in what Fraser calls social patterns of representation, interpretation, and communication. Examples include being made invisible, disrespected, and so on; therefore, remedies for cultural injustice require culturalsymbolic changes-that is, different and better recognition of differences. Fraser is astute to suggest joining together soon after her conceptual separation: cultural recognition is, in fact, a form of redistribution; furthermore, redistributive remedies presuppose a conception of recognition-that is, the equal moral worth of all persons. Fraser is not afraid to face up to the difficulties inherent in attempting to remedy injustices that are in some important ways different from one another. Socio-economic injustice demands the abolition of economic conditions that support group specificity; however, recognition entails continuing and/or enhancing differentiation.

Fraser argues that the extremes on the conceptual continuum of redistribution and recognition remedies are class and despised sexuality; however, the gray areas are characterized by hybrid modes that suggest a combination of the injuries of class and gender-constructed as the despised "other." In her words:

Bivalent collectivities in sum may suffer both socio-economic maldistribu-
tion and cultural mistecognition in forms where neither of these injustices is
an indirect effect of the other, but where both are primary and co-original. In
that case, neither redistributive remedies alone nor recognition remedies
alone will suffice. Bivalent collectivities need both.

Fraser thinks that gender and race are paradigmatic bivalent collectivities. Both are socially constructed identities rather than the result of "natural" biological facts. For example, both play important roles with regard to the divisions and stratification within paid labour, as well as the division between paid and unpaid labour. There are gender- and race-specific modes of exploitation, marginalization and deprivation; therefore, in this sense, gender and race are endowed with certain social-class characteristics. Justice requires the smashing of current job-related divisions and injustices based on race and gender. Obviously, race and gender conceived of in biological terms cannot be abolished in the same 12(1), (Fall) 1998 
way Marx's proletariat can; however, if the hostile/derogatory social constructions of biological differences are what cause injustice, these constructions can and must be abolished. This kind of analysis must become part of teaching and learning in our public schools; however, the appropriate pedagogical strategies must be decided upon by the teachers themselves.

Fraser speaks of two broad approaches for remedying injustices that cut across the redistribution-recognition divide: (1) affirmation and (2) transformation. The first is a liberal response, whereas the second is a deconstructive socialist one. She accuses the liberals of seeking to correct inequitable outcomes without dealing with the underlying realities that cause the need to create the kind of welfarism (offered as an honorific term) that Rightists attack so effectively-albeit, cruelly. This is accompanied, in her view, by mainstream multiculturalism that attempts to gain acceptance of the constructed "other" within the system as it is. Mainstream multiculturalism and all too many forms of identity politics leave unchanged not only the socio-economic injustices caused by the political economy but also the binary gender and racial codes. The transformative socialist strategy seeks to deconstruct the homo-hetero dichotomy as well as stark dichotomies between those whose colour is white and those who are coloured differently. In fact, this deconstructive strategy endeavours to destabilize all fixed sexual, social, and other identities that have been constructed by those with power vis-a-vis serviceable "others." Fraser speaks favourably of "queer theory" which aims to get beyond gay identity and on to creating a society with gray area continuums which include more people within the parameters of acceptability. Acting tolerantly and patronizingly toward the gender and racial "other" fails to problematize the tolerant patronizer's position; furthermore, it leads to a politics of resentment and backlash. Those who are treated as persons deemed irrevocably different-and allegedly worse-are never safe from those who wish to undo even a modicum of fair treatment and seek to return to blatant oppression. Those who are labelled as different usually become targets of those who consider themselves within the parameters of "normality." I trust that educators can, and will, determine for themselves how to introduce discourses such as Fraser's into appropriate pedagogical practice.

Fraser criticizes liberal affirmative redistribution strategies for being limited to altering attitudinal discrimination instead of attacking the gendered and racial world of work. The failure to alter radically the deep structures that help cause gender and racial disadvantage make necessary continuous transfer payments to certain select groups, resulting in accusations made disturbingly popular recently by spokespersons for the political Right. Conversely, the longrange goal of deconstructive feminism is to develop a culture without hierarchical constructs that serve to rank-order certain "others" to the bottom of the list. In the place of this deconstruction, Fraser would have networks of "multiple intersecting differences that are demassified and shifting. This goal is consistent with transformative socialist-feminist redistribution. Deconstruction opposes sedimentation or congealing of gender differences that occurs in an unjustly gendered political economy. Its utopian image of a culture in which every new construction of identity and difference is freely elaborated and then deconstructed is only possible on the basis of rough social equality." 25 Fraser endorses socialism as a transformative remedy because it champions universal 
social-welfare programs, effective progressive taxation, macroeconomic policies favouring full employment, a large well-funded public sector including public schools, significant public ownership, widespread participatory democracy, and the uncoupling of basic consumption shares from employment alone. These remedies are congruent with Shipper's broad and generous concept of educating the "whole child." She is convinced that transformative strategies must reduce socio-economic inequality without stigmatizing certain people as alleged undeserving beneficiaries of other people's labour and charity. This kind of society provides the context within which reciprocity, solidarity, recognition, and distribution can all develop more fully and equitably.

\section{Conclusion}

In Lives on the Boundary, Mike Rose provides a critical reflective description of his role as a teacher-one that follows Shipper's commitment to pushing educational rights to include some socio-economic rights. Rose encourages us to organize collectively in order to bring pressure on the state to fulfil its role as a representative of all the people-as opposed to a class state in the interests of the rich and powerful. His teaching experiences in East Los Angeles convinced him that a society that neither considered nor acted to promote the overall welfare of persons could not expect all students to master the narrow cognitive skills that school "experts" unfairly demand. Rose's writing assignments sought to encourage students to start from their own various experiences, as well as to reflect upon them, in part, by placing these experiences within larger contexts. He writes of the necessity and power of invitation: "Programs like the Teacher Corps-and many others that (were) developed through in the $1960 \mathrm{~s}-$ generated possibilities for all kinds of people who had traditionally been excluded from schools. "26

It secms apparent that mere inclusion, as progressive an accomplishment as it has been, is not adequate in these times. As I have written elsewhere:

Is mere inclusion into a society that itself (arguably) requires radical transformation equivalent to seeking to change the society itself? This can be stated differently: the humane thrust of the welfare-education school does not necessarily contain within it knowledge about why and how to change the economic and social class system that necessitated the ameliorative and compensatory education project in the first place. ${ }^{27}$

James Fraser has challenged his readers to talk about and enact school reform as if democracy really mattered. In his view, "a truly democratic system of education begins with a commitment to extending the best society has to offer to every citizen and at the same time ensuring that every citizen has voice and power in defining the nature of the social good itself, not merely receiving as 'best' the social good of one of the many ethnic groups." 28

Fraser understands that schooling and education for bona fide democracy must include the broadest inclusion and participation with regard to the construction of meanings, procedures, and institutions that affect each and every one of us. Her reconstructionist faith in schools may seem naive to some; however, it would be foolish for educators to dismiss his conviction that we are capable of constructing societies within which diversity is seen as a 
treasure-one that can serve to enrich us all. She believes that school classrooms can be among the "prime locations" from which to begin this construction. In the end, K-12 public schools can best serve democracy, social justice, and diversity if and when they can function within the contexts of a society that is already practicing what it would have its youngsters learn. Such a happy condition will require a long-term resolute struggle by educators, parents, ordinary citizens, as well as students-albeit in somewhat different roles from their progressive elders. These broad-based coalitions are necessary because school kids and a few brave educators cannot alone achieve the goals privileged herein. Furthermore, the responses to the historic question "What is to be done?" will be given most effectively by those who take seriously the problems and possibilities presented here and elsewhere. Those who do seek specific answers, tactics, and strategies will do so mostly within places that are familiar due to regular involvement. These tentative answers may be most helpful when and if actors also consider the relationships between local and broader contexts.

\section{Notes}

1 Henry Giroux has articulated this point well in "Benetton's 'World Without Borders': Buying Social Change,' in The Subversive Imagination: Artists, Society, and Social Responsibility, ed. Carol Becker (New York \& London: Routledge, 1994), 204-205.

2 William H. Watkins, "Multicultural Education: Toward a Historical and Political Inquiry,'” Educational Theory, 44(1), (Winter) 1994, 102.

3 Christine E. Sleeter and Carl A. Grant, "A Rationale for Integrating Race, Gender, and Class," in Class, Race, and Gender in American Education, ed. Lois Weis (Albany, NY: State University of New York Press, 1988), 156-157.

${ }^{4}$ Raymond A. Morrow and Carlos Alberto Torres, "Education and the Reproduction of Class, Gender, and Race: Responding to the Postmodernist Challenge,"' Educational Theory, 44(1), (Winter)1994, 60-61. For another work on the subject of interrelationships among class, gender, and race as well as the need to develop micro-, intermediate, and macro-theories, see Cameron McCarthy and Michael W. Apple, "Race, Class, and Gender in American Educational Research: Toward a Nonsynchronous Parallelist Position," in Class, Race, and Gender in American Education, 9-39.

5 See Clarence Page, "Next Great Task: Closing the Gap Among Blacks," Star Press (Muncie, IN), February 7, 1998, p. 4A. See, as well, the work of Adolph Reed and PBS's Frontline, "The Two Nations of Black America," featuring a discussion of class and race by William Julius Wilson, Cornell West, and Henry Louis Gates, Jr.

6 Cameron McCarthy, "Multicultural Discourses and Curriculum Reform: A Critical Perspective," Educational Theory, 44(1), (Winter) 1994, 94-95.

7 Robert Connell, "Curriculum, Politics, and Strategies of Change," unpublished manuscript, Macquarie University.

8 Carla O'Connor, "Dispositions Toward (Collective) Struggle and Educational Resilience in the Inner City: A Case Analysis of Six AfricanAmerican High School Students," American Educational Research Journal, 34(4), (Winter) 1997, 593-629. 
${ }^{9}$ Watkins, op. cit., 100.

10 For an analysis of the conflicting imperatives of democracy and capitalism upon the school and state, see Richard A. Brosio, A Radical Democratic Critique of Capitalist Education (New York: Peter Lang Publishing Company, 1994), Chapter One, "The Janus-faced Public Schools in the United States," and Chapter Two, "The Role of the State in Contemporary Capitalist and Democratic Societies: Accent, the United States."

11 Svi Shapiro, Between Capitalism and Democracy (New York: Bergin \& Garvey, 1990), 145.

12 Watkins, op. cit., 113.

13 R. W. Connell, Gender and Power: Society, the Person and Sexual Politics (Stanford: Stanford University Press, 1987), 116.

14 Kris D. Gutierrez, "Afterword," in Multicultural Education, Critical Pedagogy, and the Politics of Difference, eds. Christine E. Sleeter and Peter L. McLaren (Albany, NY: State University of New York Press, 1995), 441.

15 Watkins, op. cit., 117.

16 Holly Sklar, Chaos Or Community? Seeking Solutions, Not Scapegoats For Bad Economics (Boston: South End Press, 1995), 1.

17 "Marxism Today: An Interview With Istvan Meszaros," Monthly Review, 44(11), (April) 1993, 12.

18 Landau Rocawich, "Interview With Si Kahn," The Progressive, 58(4), (April) 1994, 30.

19 Daniel Singer, "The Antepenultimate Word . . .," The Nation, 258 (14), (April 11) 1994), 470.

20 Chantal Mouffe, cited in Stanley Aronowitz and Henry A. Giroux, Postmodern Education (Minneapolis, MN: University of Minnesota Press, 1991), 123.

21 Robin D. G. Kelley, "Identity Politics And Class Struggle," New Politics, 6(2), (Winter) 1997, 87. See Judith Butler, "Merely Cultural," New Left Review, 227, (January/February)1998, 33-44, for arguments which warn against taking new social movements, culturalism, and identity politics too lightly.

22 “'Themes," New Left Review, 212, (July/August) 1995, 1.

23 Nancy Fraser, "From Redistribution to Recognition? Dilemmas of Justice in a 'Post-Socialist' Age," New Left Review, 212, (July/August, 1995), 69. For a critique of Fraser, see Iris Marion Young, "Unruly Categories: A Critique of Nancy Fraser's Dual Systems Theory," New Left Review, 222, (March/April, 1997), 147-160. The interested reader may follow the argument in Nancy Fraser, "A Rejoinder to Iris Young," New Left Review, 223, (May/June) 1997, 126-129.

${ }^{24}$ Fraser, "From Redistribution to Recognition?," 78.

25 Ibid., 90. Teresa Amott has explained how women are especially vulnerable to economic crises, importantly because of their double roles as principle family caregiver and within the paid labour sector. The hidden injuries of this double role are not easily quantifiable according to Amott; however, "perhaps . . . because ... [ [subaltern] women have been so severely affected by the [current economic] crisis, forced to assume new burdens of work and responsibility but deprived of safety nets and guarantees, [they] have been able 
to see more clearly than those whose privileges have insulated them from its worst effects. And, finally, perhaps it is the very diversity of women's experiences that has given them a vision of alternative possibilities that is richer, more pluralistic, and more democratic." Caught In The Crisis: Women and the U.S. Economy Today (New York: Monthly Review Press, 1993), 141.

${ }^{26}$ Mike Rose, Lives on the Boundary (New York: Penguin Books, 1989), 132.

27 Brosio, A Radical Democratic Critique of Capitalist Education, 493.

28 James W. Fraser, Reading, Writing, and Justice: School Reform as If Democracy Matters (Albany, NY: State University of New York Press, 1997), 47. 